\title{
DEHP, DEP and DBP Exposure Analysis using Urinary Metabolites of Gyonggi Province University Students
}

\author{
JangWoo Lee ${ }^{* * * * *}$, YoungLim Kho**, SungKyoon Kim***, Kyungho Choi***, \\ SeongHee Hwang****, Jeeyeon Jeong*, Pangyi Kim*, \\ *Department of Occupational \& Environmental Health, Yongin University, Gyonggi-do, Korea \\ **Department of Health, Environment \& Safety, Eulji University, Gyonggi-do, Korea \\ ***School of Public Health, Seoul National University, Seoul, Korea \\ ****Department of Oriental Medical Food and Nutrition, Semyung University, Jecheon, Korea
}

\begin{abstract}
Objectives: Phthalates are used as plasticizers in polyvinyl chloride (PVC) plastics. As phthalate plasticizers are not chemically bound to the PVC, they can leach, migrate or evaporate into indoor air and atmosphere, foodstuffs, other materials, etc. Therefore, humans are exposed through ingestion, inhalation, and dermal exposure over their entire lifetime, including during intrauterine development. In particular, university students have a great number of opportunities to contact products including phthalates during campus life (food packaging, body care products, cosmetic, lotions, aftershave, perfume etc.). The purpose of this study was to examine levels of phthalate exposure as undergraduate students begin to use pharmaceuticals and personal care products including phthalates.
\end{abstract}

Methods: Phthalate metabolites, mono-ethyl phthalate (MEP), mono-n-butyl phthalate (MnBP), mono-isobutyl phthalate (MiBP), mono-2- ethylhexyl phthalate (MEHP), \{(mono-(2-ethyl-5-hydroxyhexyl) phthalate (MEHHP $\}$, and mono-(2-ethlyl-5-oxohexyl) phthalate (MEOHP $\}$ were examined. 80 urine samples collected from university students were analyzed using LC/MS/MS(API 4000, Applied Bioscience) with on-line enrichment and columnswitching techniques. This study was carried out at Y university located in Gyonggi Province from 2008 to 2011.

Results: The detection limit of phthalate metabolites were $0.03 \mathrm{ng} / \mathrm{mL}$ for MEP, $0.11 \mathrm{ng} / \mathrm{mL}$ for MnBP, $0.08 \mathrm{ng} / \mathrm{mL}$ for MiBP, $0.93 \mathrm{ng} / \mathrm{mL}$ for MEHP, $0.19 \mathrm{ng} / \mathrm{mL}$ for MEOHP and $0.16 \mathrm{ng} / \mathrm{mL}$ for MEHHP. MnBP showed the highest urinary levels (median: $31.6 \mathrm{ug} / \mathrm{L}, 24.8 \mathrm{ug} / \mathrm{g}$ creatinine (cr)). Concentrations were also high for MEHHP (median: $24.1 \mathrm{ug} / \mathrm{L}, 19.0 \mathrm{ug} / \mathrm{g} \mathrm{cr}$ ), followed by MEOHP (median: $22.8 \mathrm{ug} / \mathrm{L}, 17.9 \mathrm{ug} / \mathrm{g} \mathrm{cr}$ ). In individual cases, the maximum level reached up to $348 \mathrm{ug} / \mathrm{L}$, and $291 \mathrm{ug} / \mathrm{g} \mathrm{cr}$, respectively. The urinary and creatinine adjusted levels of MEP were lower than those for DBP and DEHP metabolites, but were higher in 95th percentiles. As a result, the mean daily DEP intake value was $2.3 \mu \mathrm{g} / \mathrm{kg}$ bw/day, $3.5 \mu \mathrm{g} / \mathrm{kg}$ bw/day for DEHP and $4.9 \mu \mathrm{g} / \mathrm{kg}$ bw/ day for DBP.

Conclusion: These students' phthalate exposure levels were below the international safe level set by the EU, but higher than the 2012 KFDA survey of the age group from 3 to 18 .

Keywords: Phthalates, university student, daily intake, urine, metabolites

\section{Introduction}

Humans are exposed to various environmental contaminants, including phthalic acid diesters, commonly known as phthalates. ${ }^{1)}$

Phthalates are well known for their high production volume, a broad range of application, and ubiquity in environment. Because of their widespread use, all

\section{Corresponding author:}

Received: 4 March 2013, Revised: 13 August 2013, Accepted: 4 September 2013 
populations of people, domestic animals, and wildlife regularly encounter opportunities for exposure to phthalate. ${ }^{2,3)}$

In Korea, $4.0 \times 10^{5}$ tons of di-2- ethylhexyl phthalate (DEHP) was produced and $1.0 \times 10^{4}$ tons of di-n-butyl phthalate (DBP) was produced in 2002. In $2006,4.4 \times 10^{5}$ tons of DEHP was produced and $1.0 \times 10^{5}$ tons is used and $7.7 \times 10^{3}$ tons of DBP was produced and $1.9 \times 10^{3}$ tons is used. The production of DEHP was increased whereas DBP was decreased. ${ }^{4)}$

Phthalate esters have adverse effects on liver, kidney, and the reproductive system, and act as weak endocrine disrupting agents. ${ }^{5)}$ DEHP exerted toxic effects on the female and male reproductive system and interfered with the development of offspring. ${ }^{6-8)}$ DBP has a lower toxic potency than DEHP with mainly developmental effects in rodents. ${ }^{9)}$ Two studies provide preliminary evidence that the urinary concentrations of phthalate monoesters were associated with damage in human sperm and reduction in sperm motility as well as with shortened anogenital distance in male infants. ${ }^{10,11)}$

An assessment of the internal phthalate exposure is generally possible by measuring the amount of specific metabolites excreted via urine., ${ }^{2,13)}$ For these biomonitering purpose specific metabolites of the phthalates, preferably in urine, can used. Since all phthalates are rapidly metabolized by cleavage of one or both of the two ester groups, metabolites like the primary monoesters are the obvious choice for analysis. However, even determination of those metabolites is susceptible to contamination, since they might be generated out of the parent diesters by various processes besides human metabolism, like chemical, enzymatical, microbiological, or photolytical hydrolysis. ${ }^{12)}$

At present a few studies review children and human exposure effects by various sources, but there are few studies for phthalate exposure of university students.

Since starting the university, undergraduate students take an interest in their physical appearance therefore they plentifully used body-care products (shampoo, body lotion, hair spray, wax and gel etc). Especially, female students frequently used to makeup products such as cosmetics, perfumes and lipsticks. And university students often eat fast-food that was put in plastic vessels and vinyl wraps. This reason include menu choices, cost, convenience, taste, socializing with friends, and a chance to get out. ${ }^{14,15)}$

The purpose of this study was to examine the level of phthalate exposure because the undergraduated students start to use the pharmaceuticals and personal care products (PPCP) including phthalates.

\section{Materials and Method}

\section{Urine sample collection}

The urine samples were independently collected in the university. More than eighty university students (19-27 years old) participated in this study and only 80 were sampled. They were not occupationally exposed to phthalates. They were living in the city of Seoul and the nearby suburban. A single spot urine sample was collected in $250 \mathrm{ml}$ beaker, and then separated into two glass tube and stored at $-20^{\circ} \mathrm{C}$ until analysis. Travel blanks were prepared and treated similarly.

\section{Chemicals}

Authentic standard substances (purity 99\%), mono-ethyl phthalate, mono-n- butyl phthalate, mono-isobutyl phthalate, mono-2- ethylhexyl phthalate, mono-(2-ethlyl-5- oxohexyl) phthalate and mono-(2-ethyl-5-hydroxyhexyl) phthalate were obtained from Cambridge Isotope Laboratories, Inc. (Andover, MA, USA) as well as authentic isotopically labeled standard substances, mono-ethyl phthalate (MEP-1, $2^{13} \mathrm{C}_{2}, 99 \%$ ), mono-n-butyl phthalate (MnBP-1, $2^{13} \mathrm{C}_{2}, 99 \%$ ), mono-isobutyl phthalate (MiBP$1,2^{13} \mathrm{C}_{2}, 99 \%$ ), mono-2-ethylhexyl phthalate (MEHP $\left.-1,2{ }^{13} \mathrm{C}_{2}, 99 \%\right)$, mono-(2-ethlyl-5-oxohexyl) phthalate (MEOHP-1, ${ }^{13} \mathrm{C}_{2}$, 99\%) and mono-(2-ethyl-5hydroxyhexyl) phthalate (MEHHP $-1,2{ }^{13} \mathrm{C}_{2}, 99 \%$ ).

Acetonitrile and water ( $>99.8 \%$, LC/MS grade) were purchased from Burdick and Jackson (Honeywell international Inc, USA). Ammonium acetate $(>97.0 \%)$ was purchased from sigma (Sigma-Aldrich Inc, USA). -glucuronidase enzyme solution (200units/ml, from Escherichia coli K12) was purchased from Roche Diagnostics (Mannheim, Germany).

\section{Sample preparation}

Each urine sample was thawed and vortex mixed, and $0.5 \mathrm{ml}$ was transferred into a brown glass test 
tube previously heated, cooled and acetone-washed. The sample was spiked with the labeled internal standard aqueous solution $(20 \mu \mathrm{l}, 1 \mu \mathrm{g} / \mathrm{ml})$, ammonium acetate aqueous solution $(100 \mu \mathrm{l}, 1 \mathrm{M})$, and $\beta$-glucuronidase enzyme solution $(10 \mu \mathrm{l}, 200$ units $/ \mathrm{ml})$. The sample was then incubated at $37^{\circ} \mathrm{C}$ for 2 hour in drying oven. The incubated sample was vortex mixed and then sonicated and the treated sample was mixed in 6:1 (sample : acetonitrile) and separated by centrifugation. Through a syringe filter $(0.2 \mu \mathrm{m}$, nylon), the sample was transferred to a glass auto-sampler vial. A method blank and a spiked urine sample for reference were also analyzed in parallel with unknown samples in each batch.

\section{LC-MS-MS analysis}

Liquid chromatography was carried out on a Nanospace SI-2 HPLC apparatus with switching valve (auto sampler, quaternary pump, vacuum degasser). The HPLC equipped a pre-column (MF C8, $4.6 \times 50 \mathrm{~mm}, 5 \mu \mathrm{m}$, Shiseido), trap-column (Cadenza C18, 2.0 $\times 30 \mathrm{~mm}, 5 \mu \mathrm{m}$, Imtakt) and analytical column (Cadenza C18, $2.0 \times 75 \mathrm{~mm}$, $3 \mu \mathrm{m}$, Imtakt). We used $0.1 \%$ formic acid (solvent A) and acetonitrile added $0.1 \%$ formic acid (solvent B) as a mobile phase with a constant flow rate $(0.6 \mathrm{ml} / \mathrm{min})$, and $20 \mu \mathrm{l}$ of sample was injected into a HPLC column using an auto sampler. ${ }^{32)}$

For each analyte at least two specific parent daughter ion combinations were monitored with one combination being used for quantification and the other(s) for verification. Parameters of the HPLCMS/MS methods for the analytes and its internal standards were used as Kho et al.. ${ }^{32)}$

\section{Data analysis \\ 1) Detection and measurement}

Identification of the phthalate monoester was based on matching with the retention time of the corresponding labeled internal standard. Analytes were quantified using isotope dilution mass spectrometry. Two personal computer-based instrument software programs, Analyst ${ }^{\circledR}$ Software v1.5 (Applied Biosystem, U.S.), were used to acquire and process the data obtained. Integration, calibration, and quantification were carried out using these software programs.

\section{2) Estimation of daily intake}

The measured concentrations of phthalate metabolites in the urine samples were then translated into the daily intakes of the corresponding diesters. We assumed steady-state exposure, as in the previously published study. ${ }^{16)}$ We employed the conversion model equation (1) as previously report. ${ }^{16,17)} \mathrm{ME}$ is the creatinine adjusted concentration of each phthalate monoester $(\mathrm{mg} / \mathrm{g} \mathrm{cr}$ ), $\mathrm{CE}$ is the personal daily creatinine excretion rate normalized by individual body weight $(\mathrm{g} / \mathrm{kg} / \mathrm{day})$, Fue is the molar fraction of the urinary excreted monoester related to the ingested diester, and MWd and MWm are the molecular weights of the phthalate diesters and monoesters:

$$
\text { Daliy Intake }=\frac{\mathrm{ME} \times \mathrm{CE}}{\text { Fue } \times 1000} \times \frac{\mathrm{MW}_{\mathrm{d}}}{\mathrm{MW}_{\mathrm{m}}}
$$

In the Equation. (1), $\mathrm{CE}$ is creatinine excretion and was set to be $18 \mathrm{mg} / \mathrm{kg} /$ day for women and $23 \mathrm{mg} /$ $\mathrm{kg} /$ day for men. ${ }^{17)}$ Fractional urinary excretion (Fue) values were provided by studies for the excretion of metabolites. $^{18,19)}$ The values were 0.13 for MEP, 0.13 for MEHP, 0.23 for MEHHP and 0.15 for MEOHP. For MBP we assumed the equal excretion factor as for MEP.

\section{3) Statistical analysis}

Considering the skewed distribution of the urinary phthalate monoesters, a natural log-transformation of data was used. The data were presented as range, median, 95th percentile, GM and GSD for the measurements and analyzed using the statistical software package Statistical Analysis System (SAS) version 8 (SAS Institute Inc., Cary, NC, USA). The Mann \& Whitney U test (Wilcoxon rank-sum test) were applied to compare phthalate metabolite levels between men and women and one way ANOVA was applied to compare those among the age groups. A spreadsheet program (Excel 2003) was used for the table style database and for calculating some of the statistics.

\section{Results}

\section{Metabolites in urine}

The urinary concentrations and creatinine adjusted of the phthalate metabolites measured are given in Table 1 and 2. Among the phthalate metabolites measured in this study, MnBP level showed the highest urinary levels (median: $31.6 \mathrm{ug} / \mathrm{L}, 24.8 \mathrm{ug} / \mathrm{g} \mathrm{cr}$ ). The 
Table 1. The concentration (ug/L) of phthalate metabolites measured in urine samples of university students

\begin{tabular}{|c|c|c|c|c|c|c|c|}
\hline Phthalate & Metabolites & $\mathrm{N}$ & sex & GM & $50 \mathrm{P}$ & $95 \mathrm{P}$ & Range \\
\hline & \multirow{3}{*}{ MEP } & 80 & sum & 16.2 & 12.5 & 188.0 & $0.7 \sim 537.0$ \\
\hline \multirow[t]{3}{*}{ DEP } & & 40 & male & 10.4 & 9.9 & 53.3 & $0.7 \sim 122.0$ \\
\hline & & 40 & female & 25.3 & 22.4 & 227.0 & $1.4 \sim 537.0$ \\
\hline & \multirow{3}{*}{ MEHP } & 80 & sum & 20.6 & 19.6 & 49.6 & $5.5 \sim 220.0$ \\
\hline \multirow[t]{9}{*}{ DEHP } & & 40 & male & 19.9 & 18.4 & 78.5 & $5.5 \sim 220.0$ \\
\hline & & 40 & female & 21.2 & 20.8 & 40.4 & $9.0 \sim 67.6$ \\
\hline & \multirow{3}{*}{ MEHHP } & 80 & sum & 24.1 & 25.5 & 67.8 & $1.8 \sim 348.0$ \\
\hline & & 40 & male & 25.2 & 27.7 & 55.7 & $4.5 \sim 348.0$ \\
\hline & & 40 & female & 23.1 & 23.2 & 67.8 & $1.8 \sim 83.3$ \\
\hline & & 80 & sum & 22.8 & 23.2 & 67.5 & 2.0 291.0 \\
\hline & MEOHP & 40 & male & 22.7 & 22.9 & 49.9 & $3.7 \sim 291.0$ \\
\hline & & 40 & female & 22.8 & 23.8 & 67.5 & $2.0 \sim 79.6$ \\
\hline & & 80 & sum & 31.6 & 35.2 & 84.5 & $4.5 \sim 204.0$ \\
\hline \multirow[t]{5}{*}{ DBP } & $\mathrm{MnBP}$ & 40 & male & 29.2 & 31.3 & 68.3 & $5.7 \sim 83.1$ \\
\hline & & 40 & female & 34.2 & 36.0 & 115 & $4.5 \sim 204.0$ \\
\hline & & 80 & sum & 8.4 & 8.9 & 22.4 & $1.4 \sim 44.5$ \\
\hline & MiBP & 40 & male & 8.1 & 8.1 & 22.2 & $1.4 \sim 44.5$ \\
\hline & & 40 & female & 8.7 & 9.6 & 22.4 & $1.4 \sim 25.1$ \\
\hline
\end{tabular}

Urine samples were available for 80 university students. In all urine samples the DEP metabolite MEP, DEHP monoester MEHP and secondary metabolites MEOHP, MEHHP and DBP metabolites MnBP, MiBP were detectable respective LOQs. The detection limit of phthalate metabolites were $0.03 \mathrm{ng} / \mathrm{mL}$ for MEP, $0.11 \mathrm{ng} / \mathrm{mL}$ for MnBP, $0.08 \mathrm{ng} / \mathrm{mL}$ for MiBP, $0.93 \mathrm{ng} / \mathrm{mL}$ for MEHP, $0.19 \mathrm{ng} / \mathrm{mL}$ for MEOHP and $0.16 \mathrm{ng} / \mathrm{mL}$ for MEHHP, respectively.

Table 2. The creatinine adjusted concentration (ug/g) of phthalate metabolites measured in urine samples of university students

\begin{tabular}{ccccccccc}
\hline \hline Phthalate & Metabolite & $\mathrm{n}$ & $\begin{array}{c}\text { Detectable } \\
(\%)\end{array}$ & GM & GSD & 50P & 95P & Range \\
\hline DEP & MEP & 80 & 100 & 12.7 & 3.7 & 8.8 & 152.0 & $0.8-291.0$ \\
DEHP & MEHP & 80 & 100 & 16.1 & 2.0 & 16.3 & 53.1 & $4.8-173.0$ \\
& MEHHP & 80 & 100 & 19.0 & 1.8 & 20.0 & 48.4 & $4.1-138.0$ \\
& MEOHP & 80 & 100 & 17.9 & 1.8 & 17.5 & 53.9 & $4.0-115.0$ \\
DBP & MnBP & 80 & 100 & 24.8 & 1.8 & 24.9 & 53.1 & $2.5-118.0$ \\
& MiBP & 80 & 100 & 6.6 & 1.8 & 6.6 & 17.4 & $1.5-27.6$ \\
\hline
\end{tabular}

concentrations were high for MEHHP (median : $24.1 \mathrm{ug} / \mathrm{L}, \quad 19.0 \mathrm{ug} / \mathrm{g} \mathrm{cr}$ ), followed by MEOHP (median : $22.8 \mathrm{ug} / \mathrm{L}, 17.9 \mathrm{ug} / \mathrm{g} \mathrm{cr}$ ). In individual base, we observed maximum level reached up to $348.0 \mathrm{ug} / \mathrm{L}, 291.0 \mathrm{ug} / \mathrm{g}$ cr, respectively. The urinary and creatinine adjusted levels of MEP were lower than those of DBP and DEHP metabolites but were higher in 95th percentile.

We can compare the urinary phthalate metabolite levels determined in our samples with those determined in population studies conducted previously in Germany and the USA (Table 3). MEP value (median $12.5 \mathrm{ug} / \mathrm{L}$ ) was lower compared with USA (median 181 and $188 \mathrm{ug} / \mathrm{L}$ ) levels. MnBP $(35.2 \mathrm{ug} / \mathrm{L})$ and $\mathrm{MiBP}(8.9 \mathrm{ug} / \mathrm{L})$ values were lower compared with Germany children (MnBP $57.4 \mathrm{ug} / \mathrm{L}$, MiBP 31.9 ug/L) but higher slightly compared to the level of USA (MnBP 19.1 20.7, MiBP 2.4 4.9 ug/L). MEHP (19.6 ug/L), MEOHP (23.2 ug/L), MEHHP $(25.5 \mathrm{ug} / \mathrm{L})$ level of this study were higher compared 
Table 3. Comparison between urinary excretion $(\mathrm{ug} / \mathrm{L})$ of the phthalate metabolites in the German and Korea generation population

\begin{tabular}{|c|c|c|c|c|c|c|c|c|}
\hline Study & \multicolumn{2}{|c|}{ CDC NHANES (2005) } & \multicolumn{2}{|c|}{ Wittassek et al. (2007) } & \multicolumn{2}{|c|}{ CDC NHANES (2009) } & \multicolumn{2}{|c|}{ This study } \\
\hline \multirow{3}{*}{$\begin{array}{c}\text { Country } \\
\text { Sampling } \\
\text { year } \\
\text { N (age) }\end{array}$} & \multicolumn{2}{|c|}{ USA } & \multicolumn{2}{|c|}{ Germany } & \multicolumn{2}{|c|}{ USA } & \multicolumn{2}{|c|}{ Korea } \\
\hline & \multicolumn{2}{|c|}{$\begin{array}{l}2001-2002 \\
1683(>20)\end{array}$} & \multicolumn{2}{|c|}{$\begin{array}{l}2001 / 2003 \\
120(20-29)\end{array}$} & \multicolumn{2}{|c|}{$\begin{array}{l}2003-2004 \\
1534(>20)\end{array}$} & \multicolumn{2}{|c|}{$\begin{array}{c}2008 \\
80(19-27)\end{array}$} \\
\hline & $50 \mathrm{P}$ & $95 \mathrm{P}$ & $50 \mathrm{P}$ & $95 \mathrm{P}$ & $50 \mathrm{P}$ & $95 \mathrm{P}$ & $50 \mathrm{P}$ & $95 \mathrm{P}$ \\
\hline MEP & 181 & 2720.0 & - & - & 188.0 & 2980.0 & 12.5 & 188.0 \\
\hline $\mathrm{MnBP}$ & 19.1 & 95.4 & 57.4 & 338.0 & 20.7 & 108 & 35.2 & 84.5 \\
\hline MiBP & 2.4 & 16.3 & 31.9 & 132.0 & 3.9 & 19.9 & 8.9 & 22.4 \\
\hline MEHP & 4.1 & 39.5 & 5.0 & 28.6 & 1.7 & 29.5 & 19.6 & 49.6 \\
\hline MEOHP & 12.2 & 115.0 & 13.4 & 42.3 & 12.4 & 139.0 & 23.2 & 67.5 \\
\hline MEHHP & 17.7 & 175.0 & 14.6 & 58.6 & 18.4 & 225.0 & 25.5 & 67.8 \\
\hline
\end{tabular}

Table 4. Daily intakes ( $\mu \mathrm{g} / \mathrm{kg}$ bw/day) of phthalate metabolites measured in urine samples of university students

\begin{tabular}{cccccccccc}
\hline \hline \multirow{2}{*}{ Chemicals } & \multicolumn{3}{c}{ Male $(\mathrm{n}=40)$} & \multicolumn{3}{c}{ Female $(\mathrm{n}=40)$} & \multicolumn{3}{c}{ Total $(\mathrm{n}=80)$} \\
\cline { 2 - 10 } & GM & GSD & Range & GM & GSD & Range & GM & GSD & Range \\
\hline MEP & 1.5 & 2.8 & $0.2-30.7$ & 3.5 & 3.8 & $0.6-46.2$ & 2.3 & 3.5 & $0.2-46.2$ \\
MEHP & 3.5 & 1.9 & $1.2-43.0$ & 3.6 & 1.9 & $1.1-17.2$ & 3.5 & 1.9 & $1.1-43.0$ \\
MEHHP & 2.3 & 1.7 & $0.8-18.2$ & 2.1 & 1.9 & $0.4-6.4$ & 2.2 & 1.8 & $0.4-18.2$ \\
MEOHP & 3.3 & 1.7 & $1.0-23.6$ & 3.2 & 1.9 & $0.7-9.9$ & 3.2 & 1.8 & $0.7-23.6$ \\
MnBP* & 4.5 & 1.6 & $2.2-12.5$ & 5.2 & 1.9 & $0.4-20.4$ & 4.9 & 1.7 & $0.4-20.4$ \\
MiBP & 1.3 & 1.8 & $0.3-6.1$ & 1.3 & 1.7 & $0.4-3.5$ & 1.3 & 1.8 & $0.3-6.1$ \\
\hline
\end{tabular}

* $\mathrm{P}<0.05$ (one-way analysis of variance for daily intakes).

with USA (1.7 4.1, 12.2 12.4, $17.7 \sim 18.4 \mathrm{ug} / \mathrm{L}$ respectively) and Germany (5.0, 13.4, $14.6 \mathrm{ug} / \mathrm{L})$.

\section{Daily intake estimations}

From the urinary phthalate metabolite levels we extrapolated daily intakes of the parent phthalates (DEP, DEHP. DBP), individually for each subject (Table 4). Overall, we found that DBP showed the highest daily intake values (mean : $1.3-4.9 \mu \mathrm{g} / \mathrm{kg}$ bw/day), follow by DEHP (mean : 2.2-3.5 $\mu \mathrm{g} / \mathrm{kg}$ bw/day) and the daily intake of DEP was $2.3 \mu \mathrm{g} / \mathrm{kg}$ bw/day.

But DEP had about 2 8 times high daily intakes than those of DEHP and DBP in 95th percentile value. And we compared the daily intakes obtained with exposure limit values deduced by US EPA (EPA, 1990, 1991, 1993). The daily intakes of DEP, DBP were clearly lower than the RfD of US EPA ( $800 \mathrm{ug} / \mathrm{kg}$ bw/day, $100 \mathrm{ug} / \mathrm{kg}$ bw/day). The maximum intake value for DEHP of $43.0 \mathrm{ug} / \mathrm{kg}$ bw/day was 2 time higher than the RfD of US EPA and 2.5\% (2 subjects out of 80 ) exceeded.
We compared the daily intakes of the different phthalate metabolites between the gender (Table 5). Female subjects had higher daily intakes for the DBP which can be calculated from the MnBP metabolites $(\mathrm{P}<0.05)$. The major routes of phthalate exposure are thought to be ingestion through dietary or dermal or respiratory sources.

In MEP, 22 22 age group had highest daily intake and 3 time higher at median than those of 25 27 age group. MnBP was 3 4 times higher than those of MiBP in all age groups. At median, 23 24 age group had highest daily intake in MEHHP and MEOHP and 21 22 age group was the highest in MEHP.

\section{Discussions}

The concentrations were highest for MEHHP (median: $24.1 \mathrm{ug} / \mathrm{L}, 19.0 \mathrm{ug} / \mathrm{g} \mathrm{cr}$ ), followed by MEOHP (median: $22.8 \mathrm{ug} / \mathrm{L}, 17.9 \mathrm{ug} / \mathrm{g}$ cr). In individual cases we observed maximum levels reaching up to 
Table 5. Daily intakes ( $\mu \mathrm{g} / \mathrm{kg}$ bw/day) of phthalate metabolites measured in urine samples of university students classified by age

\begin{tabular}{|c|c|c|c|c|c|c|}
\hline \multirow{2}{*}{ phthalate } & \multirow{2}{*}{ age } & \multirow{2}{*}{$\mathrm{N}$} & \multicolumn{4}{|c|}{ Daily intake (ug/kg bw/day) } \\
\hline & & & GM(GSD) & Median & P95 & Range \\
\hline \multirow{4}{*}{ MEP } & $19-20$ & 18 & $1.8(4.0)$ & 1.5 & 27.7 & $0.2-40.0$ \\
\hline & $21-22$ & 24 & $3.3(3.4)$ & 3.6 & 20.7 & $0.7-30.7$ \\
\hline & $23-24$ & 21 & $3.0(3.8)$ & 2.8 & 40.7 & $0.5-46.2$ \\
\hline & $25-27$ & 17 & $1.2(2.2)$ & 1.1 & 4.1 & $0.3-4.3$ \\
\hline \multirow{4}{*}{ MEHP } & $19-20$ & 18 & $3.4(1.5)$ & 3.7 & 6.3 & $1.5-6.5$ \\
\hline & $21-22$ & 24 & $3.5(2.0)$ & 4.2 & 10.1 & $1.2-13.8$ \\
\hline & $23-24$ & 21 & $3.9(2.3)$ & 3.1 & 17.2 & $1.1-43.0$ \\
\hline & $25-27$ & 17 & $3.4(3.4)$ & 3.3 & 8.7 & $1.5-10.8$ \\
\hline \multirow{4}{*}{ MEHHP } & $19-20$ & 18 & 2.1(1.9) & 2.1 & 5.3 & $0.4-6.4$ \\
\hline & $21-22$ & 24 & 2.2(1.9) & 2.3 & 5.4 & $0.5-5.6$ \\
\hline & $23-24$ & 21 & $2.4(1.6)$ & 2.6 & 5.0 & $0.9-5.5$ \\
\hline & $25-27$ & 17 & $2.2(2.0)$ & 2.4 & 6.5 & $0.8-18.2$ \\
\hline \multirow{4}{*}{ MEOHP } & $19-20$ & 18 & $3.2(1.9)$ & 3.1 & 7.9 & $0.6-9.9$ \\
\hline & $21-22$ & 24 & $3.2(2.0)$ & 3.2 & 8.7 & $0.8-9.4$ \\
\hline & $23-24$ & 21 & $3.5(1.6)$ & 3.6 & 7.1 & $1.6-7.4$ \\
\hline & $25-27$ & 17 & $3.0(1.9)$ & 3.0 & 9.2 & $1-23.6$ \\
\hline \multirow{4}{*}{$\mathrm{MnBP}^{*}$} & $19-20$ & 18 & $4.4(1.7)$ & 4.4 & 9.0 & $1.1-10.5$ \\
\hline & $21-22$ & 24 & $4.8(1.9)$ & 5.5 & 7.9 & $0.4-9.9$ \\
\hline & $23-24$ & 21 & $6.4(1.6)$ & 5.7 & 13.1 & $2.5-20.4$ \\
\hline & $25-27$ & 17 & $4.0(1.5)$ & 4.0 & 8.1 & $2.3-12.5$ \\
\hline \multirow{4}{*}{ MiBP } & $19-20$ & 18 & $1.2(1.9)$ & 1.4 & 2.6 & $0.4-3.6$ \\
\hline & $21-22$ & 24 & $1.4(1.8)$ & 1.4 & 3.0 & $0.5-6.1$ \\
\hline & $23-24$ & 21 & $1.4(1.7)$ & 1.3 & 3.1 & $0.5-3.5$ \\
\hline & $25-27$ & 17 & $1.1(1.8)$ & 1.0 & 2.4 & $0.3-4.5$ \\
\hline
\end{tabular}

* $\mathrm{P}<0.05$ (one-way analysis of variance for daily intakes).

$348 \mathrm{ug} / \mathrm{L}, 291 \mathrm{ug} / \mathrm{g}$, respectively, These observations are similar to those of Wittassek et al.. ${ }^{34)}$ In our study, we found low amounts of MnBP and MiBP with a 15-fold lower level of MnBP and MiBP compared to the NHANES 2001-2002, 2003-2004 data. The difference of the results cause by different pattern and exposure pathways of DEP in the USA population. And the DBP metabolite levels in our study were higher than those of NHANES 2005, 2009, whereas were lower than those of Wittassek et al. ${ }^{34)}$ Apart from the result of Wittassek et al., ${ }^{34)}$ the medians for the our data were higher than those of NHANES 2005, 2009, but were lower in 95th percentile. This may be caused by a different extent of exposure, but may also be due to different origin or age distribution of the study populations.

In generally female subjects had higher daily intakes for the DBP which can be deduced from the MnBP metabolites $(\mathrm{P}<0.05)$. These observations confirm the findings of Koch et al. ${ }^{13)}$ and Wittassek et al., ${ }^{34)}$ who estimated elevated values of DBP for females as well. Women had higher daily intake values also DEP, but the difference was not significant. The major routes of phthalate exposure are thought to be ingestion through dietary sources, but recent evidence suggests that dermal absorption may also be a major route of exposure for people. $^{28,29)}$

Dermal absorption from phthalate -containing personal care products such as sunscreen, perfume, shampoo, and cosmetics may be an important route of exposure for university students. Several animal studies were reported that slow phthalate absorption and toxicity ${ }^{30}$ but dermal absorption studies in humans are a few. Janjua and colleagues (2007) recently conducted a study of dermal absorption in healthy adults males and found a significant increase in MEP and MBP metabolites several hours after 
Table 6. Daily intakes ( $\mu \mathrm{g} / \mathrm{kg}$ bw/day) of phthalates by the German and Korea university students deduced from urinary metabolite concentrations.

\begin{tabular}{|c|c|c|c|c|c|c|}
\hline \multirow{5}{*}{$\begin{array}{c}\text { Study } \\
\text { Country } \\
\text { Sampling year } \\
\text { n(age) }\end{array}$} & \multicolumn{4}{|c|}{ Wittassek et $a l .^{34)}$} & \multicolumn{2}{|c|}{ This study } \\
\hline & \multicolumn{4}{|c|}{ Germany } & \multicolumn{2}{|c|}{ Korea } \\
\hline & \multirow{2}{*}{\multicolumn{2}{|c|}{$\begin{array}{l}1988-1993 \\
240(20-29)\end{array}$}} & \multirow{2}{*}{\multicolumn{2}{|c|}{$\begin{array}{l}2001 / 2003 \\
119(20-29)\end{array}$}} & \multirow{2}{*}{\multicolumn{2}{|c|}{$\begin{array}{c}2008 \\
80(19-27)\end{array}$}} \\
\hline & & & & & & \\
\hline & $50 \mathrm{P}$ & $95 \mathrm{P}$ & $50 \mathrm{P}$ & $95 \mathrm{P}$ & $50 \mathrm{P}$ & $95 \mathrm{P}$ \\
\hline DEP & - & - & - & - & 1.6 & 25.8 \\
\hline DEHP & $4.2^{\mathrm{a}}$ & $12.6^{\mathrm{a}}$ & $2.7^{\mathrm{a}}$ & $6.4^{\mathrm{a}}$ & $3.5^{\mathrm{b}}$ & $10.5^{b}$ \\
\hline DBP & 6.9 & 22.2 & 2.2 & 7.3 & 4.9 & 9.9 \\
\hline
\end{tabular}

a Value based on MEHP, 5OH-MEHP, 5oxo-MEHP; metabolic conversion factor of Koch et al. (2005) applied.

b Value based on MEHP; metabolic conversion factor of Anderson et al. (2001) applied.

Table 7. Comparison of the daily intake value calculated in our study with those of Koch et al.(2000) and Wittassek et al.

\begin{tabular}{|c|c|c|c|c|c|c|}
\hline \multirow{3}{*}{$\begin{array}{l}\text { Study } \\
\text { n(age) }\end{array}$} & \multirow{2}{*}{\multicolumn{2}{|c|}{$\begin{array}{c}\text { Koch et al. }{ }^{17)} \\
\text { (NHANES III, 1988-1994) } \\
289(20-60)\end{array}$}} & \multicolumn{2}{|c|}{$\begin{array}{c}\text { Wittassek et al. }{ }^{34)} \\
\text { Koch et } a l^{35)}\end{array}$} & \multicolumn{2}{|c|}{ This study } \\
\hline & & & & & \multicolumn{2}{|c|}{$80(19-27)$} \\
\hline & $50 \mathrm{P}$ & $95 \mathrm{P}$ & $50 \mathrm{P}$ & $95 \mathrm{P}$ & $50 \mathrm{P}$ & $95 \mathrm{P}$ \\
\hline DEP & 12 & 110 & - & - & 1.6 & 25.8 \\
\hline DEHP & $0.71^{\mathrm{c}}$ & $3.6^{\mathrm{c}}$ & $4.3^{\mathrm{d}}$ & $15.2^{\mathrm{d}}$ & $3.5^{\mathrm{b}}$ & $10.5^{\mathrm{b}}$ \\
\hline DBP & $1.5^{\mathrm{a}}$ & $7.2^{\mathrm{a}}$ & 4.1 & 14.9 & 4.9 & 9.9 \\
\hline
\end{tabular}

a Sum of DnBP and DiBP

b Value based on MEHP; metabolic conversion factor of Anderson et al. (2001) applied.

c Value based on MEHP; metabolic conversion factor of Peck and Albro (1982) applied.

d Value based on MEHP, 5OH-MEHP, 5oxo-MEHP; metabolic conversion factor of Koch et al. (2005) applied.

application of phthalate containing personal care products on the skin. These authors concluded that systemic uptake through skin is likely to be an important route of exposure for humans. ${ }^{31)}$

The daily intake (ug/kg bw/day) of the DEP, DBP, DEHP are presented for different age groups in Table 6. Except for 25-27 age group, geometric means of all phthalate metabolites increase with increasing age. 21-22 and 23-24 groups were the highest daily intake in all phthalates.

We compared the daily intake of phthalates between the German and Korea university students (Table 6). The daily DEHP intakes estimated for 240 students (subset 1988-1993) in German were higher level than our data, whereas the value for 119 students (subset 2001, 2003) were somewhat lower. The estimated daily intakes for DBP were similar to those that compared our data with those of DEHP. These finding indicated that the Korean university students had higher DEHP and DBP exposure in comparison to the Germany. The differences in internal exposure between our study group and the German students are probably caused by different degrees of external exposure and also by differences in sampling location and time. The daily intake level of university students in our study differs from previously literatures for the children and adult by Koch et al. ${ }^{17)}$ and Wittassek et al. ${ }^{34)}$ (Table 7).

The 2011 survey of KFDA reported that phthalate exposure level of age group from 3 to 18 , total 1,030 childrens were DEHP $2.75 \mathrm{ug} / \mathrm{kg}$ bw/day, DBP 1.22 $\mathrm{ug} / \mathrm{kg}$ bw/day, respectively. The international safe level of phthalates from EU were DEHP $50 \mathrm{ug} / \mathrm{kg}$ bw/day, DBP $10 \mathrm{ug} / \mathrm{kg}$ bw/day. This study level were below the safe level.

The DEHP daily intakes of university students in this study was higher compared to the adult, ${ }^{13)}$ whereas lower than those of children, ${ }^{34)}$ Koch et $a l .{ }^{35)}$ The daily DBP intake of university students were similar to children in median, but higher in 95th percentile. These finding indicated that children had the highest DEHP and DBP daily intakes, 
follow by university students. And DEP was the highest in adult.

We quantified six monoesters, three DEHP metabolites, two DBP metabolites, and one DEP metabolite in undergraduate students urine sample. Incidentally, because of the problem of contamination and the high blank values, phthalate diesters determinations have only been applicable for determining phthalates in highly exposed subjects. Therefore monoesters of phthalates are generally more suitable as parameters for phthalate exposure, since they are primary metabolites of the diesters and specific to the respective parent phthalate diester. ${ }^{12,20,21)}$

Those monoesters, however, are also subject to contamination in the analytical and preanalytical phase as described above. During sample collection, transportation and the analytical sample preparation phthalate monoesters might be generated out of the ubiquitously present phthalate diesters through simple chemical, microbiological, or enzymatical ester cleavage and not human metabolism. Blount et $a l .,{ }^{12)}$ determined various monoester metabolites of the most applied phthalates.

MBP has a structural isomer, MiBP. MiBP and MBP were chromato- graphically inseparable in the present study. The complete chromatographic separation of MBP and MiBP can be achieved using a lower flow rate and a gentle slope gradient, ${ }^{22)}$ or by using gas chromatography with a capillary column. ${ }^{23)}$

Achieving complete chromatographic separation of MBP and MiBP using these methods should be attempted in the future.

In the present study, we measured MEHP, MEHHP and MEOHP as an analytical standard substance. However, MEHP, the primary metabolite of DEHP, is not always our best choice as a biomarker for exposure to DEHP. Secondary metabolites of DEHP are also more important biomarkers for exposure to DEHP according to earlier studies. $^{24,25,26,27)}$

These secondary metabolites of DEHP can be more suitable than MEHP because they are excreted in much higher concentrations in human urine (2.9 times higher), they show longer halflife times of elimination and they are not susceptible to any source of contamination.

We have to point out that this study does not represent the general university students in Korea because of the small sample size and limited geographic area.

\section{Conclusion}

We measured MEP, MnBP, MiBP, MEHP, MEOHP and MEHHP in urine of eighty university students (20-27 years old).

We found that MnBP the highest urinary levels (median: $31.6 \mathrm{ug} / \mathrm{L}, 24.8 \mathrm{ug} / \mathrm{g} \mathrm{cr}$ ), and the urinary levels of MiBP was clearly lower than those of other metabolites. The concentrations were high for MEHHP (median : $24.1 \mathrm{ug} / \mathrm{L}, 19.0 \mathrm{ug} / \mathrm{g} \mathrm{cr}$ ), followed by MEOHP (median : $22.8 \mathrm{ug} / \mathrm{L}, 17.9 \mathrm{ug} / \mathrm{g} \mathrm{cr}$ ). We observed maximum levels reached up to $348.0 \mathrm{ug} / \mathrm{L}$, $291.0 \mathrm{ug} / \mathrm{g} \mathrm{cr}$, respectively. The urinary and creatinine adjusted level of MEP was lower than those of DBP and DEHP metabolites but the 95th percentile level of MEP was higher than DBP or DEHP.

Compared to the data of former studies, the daily DEHP and DBP intakes estimated for 240 students (subset 1988-1993) in German were higher compared to this data. And the daily DEHP and DBP intakes estimated for children in German were higher than those of university students in Korea, whereas the value for general population were somewhat lower. And compared to the data of adults, university students were higher than the adults. Female students had higher daily intakes for the DBP which can be calculated from the MnBP metabolites $(\mathrm{P}<0.05)$. This college student levels of phthalates were lower than the international safe level of EU, but somewhat higher than children of Korea.

\section{Acknowledgment}

We especially thank the students participated in this study at Y. University. Some parts of this study was supported by KFDA Grants 2007 (07142독관 리558) and Yongin University. Research Foundation Fund 2011.

\section{Reference}

1. Hiroaki Itoh, Kikuo Yoshida, Shigeki Masunaga. Evaluation of the effect of governmental control of human exposure to two phthalates in Japan using a urinary biomarker approach. International Journal 
of Hygiene Environmental Health. 2005; 208: 237245.

2. CDC, (2005). Third National Report on Human Exposure to Environmental Chemicals. Department of Health and Human Services. Centers for Disease Control and Prevention (CDC), Atlanta, GA.

3. Ted Schettler. Human exposure to phthlalates via consumer products. International Journal of Andrology, 2006; 29: 134-139.

4. Ministry of Environment Republic of Korea (2006), The amount of endocrine disruptor in 2006.

5. Hauser, R., Calafat, A. Phthalates and human health. Occupational Environmental Medicine 2005; 62: 806-818.

6. Poon, R., Lecavalier, P., Mueller, R., Valli, V.E., Procter, B.G., Chu, I. Subchronic oral toxicity of di-n-octyl phthalate and di(2-ethylhexyl) phthalate in the rat. Food and Chemical Toxicology 1997; 35: 225-239.

7. Lovekamp-Swan, T., Davis, B. Mechanisms of phthalate ester toxicity in the female reproductive system. Environmental Health Perspectives 2003; 111, 139-145.

8. Akingbemi, B.T., Ge, R., Klinefelter, G.R., Zirkin, B.R., Hardy, M.P. Phthalate-induced leydig cell hyperplasia is associated with multiple endocrine disturbances. Proceeding National Academy of Science, 2004; 101: 775-780.

9. CERHR. (2000). National Toxicology Program.CERHR Expert Panel Report on Di-n-Butyl Phthalate. NTP Center for the Evaluation of Risks to Human Reproduction, NC.

10. Duty, S.M., Silva, M.J., Barr, D.B., Brock, J.W., Ryan, L., Chen, Z., Herrick, R.F., Christiani, D.C., Hauser, R. Phthalate exposure and human semen parameters. Epidemiology 2003; 14: 269-277.

11. Swan, S.H., Main, K.M., Liu, F., Stewart, S.L., Kruse, R.L., Calafat, A., Mao, C.S., Redmon, J.B., Ternand, C.L., Sullivan, S., Teague, J.L., and the Study for Future Families Research Team. Decrease in anogenital distance among male infants with prenatal phthalate exposure. Environmental Health Perspectives 2005; 113: 1056-1061.

12. Blount, B.C., Silva, M.J., Caudill, S.P., Needham, L.L., Pirkle, J.L., Sampson, E.J., Lucier, G.W., Jackson, R.J., Brock, J.W. Levels of seven urinary phthalate metabolites in a human reference population. Environmental Health Perspectives 2000a,b; 108, 979-982.

13. Koch, H.M., Rossabach, B., Drexler, H., Angerer, J. Internal exposure of the general population to

http://www.kseh.org/
DEHP and other phthalates-determination of secondary and primary phthalate monoester metabolites in urine. Environmental Research 2003c; 93: 177-185.

14. Sneed J, Holdt CS. Many factors influence college students' eating patterns. Journal of American Diet Association, 1991; 91: 1380.

15. Hertzler AA, Frary RB. Family factors and fat consumption of college students. Journal of American Diet Association, 1996; 96: 711-4.

16. David, R.M. Exposure to phthalate esters. Environmental Health Perspectives 2000; 108: A440.

17. Koch, H.M., Drexler, H., Angerer, J. An estimation of the daily intake of di(2-ethylhexyl)phthalate (DEHP) and other phthalates in the general population. International Journal of Hygiene and Environmental. Health 2003a; 206: 77-83.

18. Kohn MC, Parham F, Masten SA, Portier CJ, Shelby MD, Brock JW, Needham LL. Human exposure estimates for phthalates. Environmental Health Perspectives 2000; 108: A440-A442.

19. Calafat AM, McKee RH, Integrating biomonitoring exposure data into the risk assessment process : phthalate [diethyl phthalate and di(2-ethylhexyl)phthalate] as a case study. Environmental Health Perspectives 2006; 114: 1783-1789.

20. Kessler, W., Phokha, W., Csanady, G.A., Filser, J.G. No background concentrations of di(2-ethylhexyl) phthalate and mono(2-ethylhexyl)phthalate in blood of rats. Archives of Toxicology. 2001; 75(1): 62-64.

21. Anderson, W.A., Castle, L., Scotter, M.J., Massey, R.C., Springall, C. A biomarker approach to measuringhuman dietary exposure to certain phthalate diesters. Food Additives and Contaminants. 2001; 18(12): 1068-1074.

22. Silva, M.J., Slakman, A.R., Reidy, J.A., Preau Jr., J.L., Herbert, A.R., Samandar, E., Needham, L.L., Calafat, A.M. Analysis of human urine for fifteen phthalate metabolites using automated solid-phase extraction. Journal of Chromatography. B Analytical Technology in Biomedical Life Science. 2004b; 805(1): 161-167.

23. Suzuki, T., Yaguchi, K., Suzuki, S., Suga, T. Monitoring of phthalic acid monoesters in river water by solid-phase extraction and GC-MS determination. Environmental Science and Technololgy. 2001; 35(18): 3757-3763.

24. Barr, D.B., Silva, M.J., Kato, K., Reidy, J.A., Malek, N.A., Hurtz, D., Sadowski, M., Needham, L.L., Calafat, A.M. Assessing human exposure to phthalates using monoesters and their oxidized metabolites as biomarkers. Environmental Health

J Environ Health Sci 2013: 39(5): 408-417 
Perspectives 2003; 111(9): 1148-1151.

25. Dirven, H.A., van den Broek, P.H., Jongeneelen, F.J., Determination of four metabolites of the plasticizer di(2-ethlyhexyl) phthalate in human urine samples. International Archives in Occupational and Environmental Health. 1993; 64(8): 555-560.

26. Preuss, R., Koch, H.M., Angerer, J. Biological monitoring of the five major metabolites of $\mathrm{di}(2-$ ethlyhexyl) phthalate (DEHP) in human urine using column- switching liquid chromatography-tandem mass spectrometry. Journal Chromatograpy. 2005; B816: 269-280.

27. Kato, K., Silva, M.J., Reidy, J.A., Hurtz III, D., Malek, N.A., Needham, L.L., Nakazawa, H., Barr, D.B., Calafat, A.M. Mono(2-ethyl-5-hydroxyhexyl) phthalate and mono-(2-ethyl-5-oxohexyl) phthalate as biomarkers for human exposure assessment to di-(2-ethylhexyl) phthalate. Environmental Health Perspectives. 2004; 112(3): 327330.

28. Schettler T. Human exposure to phthalates via consumer products. International Journal Andrology, 2006; 29(1): 134-9, discussion 81-5.

29. Wormuth M, Scheringer M, Vollenweider M, Hungerbuhler $\mathrm{K}$. What are the sources of exposure to eight frequently used phthalic acid esters in Europeans? Risk Analysis, 2006; 26(3): 803-24.

30. Elsisi AE, Carter DE, Sipes IG. Dermal absorption of phthalate diesters in rats. Fundamental and Applied Toxicology, 1989; 12(1): 70-7.

31. Janjua NR, Mortensen GK, Andersson AM, Kongshoj B, Skakkebaek NE, Wulf HC. Systemic uptake of diethyl phthalate, dibutyl phthalate, and butyl paraben following whole-body topical application and reproductive and thyroid hormone levels in humans. Environmental Science and Technology, 2007; 41(15): 5564-70.

32. Kho, Y.L, Jeong, J.Y., Choi, K.H, Kim, P.G., Determination of phthalate metabolites in Korean children's urine by HPLC with triple quadrupole tandem mass spectrometry. Journal of Environmental Health Sciences. 34(4), 271-278, 2008.

33. CDC, (2009). Forth National Report on Human Exposure to Environmental Chemicals. Department of Health and Human Services. Centers for Disease Control and Prevention (CDC), Atlanta, GA.

34. Matthias Wittassek, Gerhard Andress Wiesmüller, Holger Martin Koch, Rolf Eckard, Lorenz Dobler, Johannes Müller, Jürgen Angerer, Christoph Schlüter. Internal phthalate exposure over the last two decades - A retrospective human biomonitoring study. International Journal of Hygiene and Environmental Health 2007; 210: 319-333.

35. Koch, H.M., Becker, K., Wittassek, M., Seiwert, M., Angerer, J., Kolossa-Gehring, M., 2007a. Din-butylphthalate (DnBP) and butylbenzylphthalate (BBzP).urinary metabolite levels and estimated daily intakes: pilot study for the German Environmental Survey on children (GerES IV). Journal of Exposure Science and Environmental Epidemiology, published online 27 September 2006, doi:10.1038/sj.jes.7500526. 